\title{
Training of Ultrasound in Neonatology: Global or Local?
}

\author{
Milan Stanojevic
}

\begin{abstract}
From the beginning of its use in neonatology, ultrasound is used more frequently and for many indications. Number of indications is increasing from year to year, while the training opportunities and curricula are not following the same trend. Nowadays ultrasound has been used for determination of functional hemodynamics in critically sick neonates which increases educational burden on the young neonatologists. This only applies to the developed countries where neonatology is well developed, while in low income so called developing countries some basic health problems of neonates have not been solved and there is substantial lack of health care professionals and equipment as well.
\end{abstract}

Keywords: Ultrasound, Neonatology, Education.

How to cite this article: Stanojevic M. Training of Ultrasound in Neonatology: Global or Local? Donald School J Ultrasound Obstet Gynecol 2013;7(3):338-345.

\section{Source of support: $\mathrm{Nil}$}

Conflict of interest: None declared

\section{Global Issues in Neonatal Health: Inequity and Unrecognized Priorities}

In many low income countries newborn babies face difficult odds in living past the first month of life. A bout 3.8 million deaths occur every year in babies younger than 28 days-of which $99 \%$ are in the developing world-and deaths in the first month of life account for $42 \%$ of deaths in children younger than 5 years. ${ }^{1-5}$

Few countries have reliable national preterm birth prevalence data. Globally, an estimated 13 million babies are born before 37 completed weeks of gestation annually. Rates are generally highest in low- and middle-income countries, and increasing in some middle- and high-income countries, particularly the A mericas. ${ }^{6}$ Preterm birth is the leading direct cause of neonatal death $(27 \%)$; more than 1 million preterm newborns die annually. Preterm birth is also the dominant risk factor for neonatal mortality, particularly for deaths due to infections. Important critical issue is the value put on a baby's life-a newborn baby remains the most vulnerable human and a preterm newborn is even more vulnerable. D ata al one will not result in change until society and leaders recognize that these deaths are a loss that can and must count and be prevented. ${ }^{6,7}$ Compared to the year 2000, in the year 2010 more attention has been paid to survival of newborns, which is shown in the Table 1. ${ }^{6,8}$ In the year 2000 there was a lack of data on neonatal health issues, and timely interventions were too complex. In the year 2010 the data are clear and the solutions are doable. ${ }^{7} \mathrm{~A}$ recent data on 250,000 disbursements of aid from 2002 to 2010 showed that, before the year 2005, the word 'newborn' barely occurred. ${ }^{7}$ W hile mention of newborns has since increased, only $0.01 \%$ of about 6 billion US dollars in aid refers to newborn care interventions that would reduce infant mortality. ${ }^{7}$ It seems that before the deadline for the M illennium D evelopment Goals, global and national leaders are waking up to the urgency and the opportunity of investing in newborns. ${ }^{7}$ If newborns survive, their families are more likely to choose to have fewer children. ${ }^{7}$ If they are healthy, the nation becomes stronger. $M$ eeting goals for preventable child deaths is more and more dependent on targeting newborns. ${ }^{7}$

Less than $5 \%$ of the world's births occur in countries with complete vital registration or networks of representative, facility-based data. O ne-third of the world's births occur at home. ${ }^{6}$ Therefore, global-level data rely heavily on household surveys and modeled estimates. ${ }^{6}$

While in the high-income countries many health issues of even extremely immature preterm babies have been successfully solved, in low income countries term babies are at great risk for survival because of unavailability of health care including coverage of basic health care needs.

In such circumstances the situation of neonatal health is quite different in low-, middle- and high-income countries which should be taken under consideration when discussing different educational, heal th care and other needs. Therefore in this paper the training in neonatal ultrasound will be discussed only from the point of view of developed, highincome countries where expensive ultrasound equipment for neonatal assessment is available. Besides the unavailability of the equipment in low-income countries, there is also lack of health care professionals who could use the equipment in order to increase the survival of newborns in whom its' usage is indicated. There are much more basic heal th care needs in low-income countries which should be solved before introduction of that kind of sophisticated assessment.

\section{Some Important Historical Facts about Neonatal Ultrasound}

At the beginning of 1980s, opened anterior fontanelle has been used as an acoustic window for brain assessment of small premature and critically sick newborns. ${ }^{9-13}$ This was a substantial step forward in neonatal neuroimaging diagnostics. 
Training of Ultrasound in Neonatology: Global or Local?

Table 1: Global attention to newborn survival in the years 2000 and $2010^{6,8}$

\begin{tabular}{|c|c|c|}
\hline & Year 2000 & Year 2010 \\
\hline \multicolumn{3}{|l|}{ Actor power } \\
\hline Network & $\begin{array}{l}\text { Few individuals working on issue } \\
\text { and doing so in isolation }\end{array}$ & $\begin{array}{l}\text { Informal network provides global leadership on } \\
\text { issue }\end{array}$ \\
\hline Guiding institution & No guiding institution for issue & $\begin{array}{l}\text { Effective global guiding institution in the form of the } \\
\text { saving newborn lives program }\end{array}$ \\
\hline \multicolumn{3}{|l|}{ Ideas } \\
\hline Category creation & $\begin{array}{l}\text { Neonates are not recognized as } \\
\text { a global health category }\end{array}$ & $\begin{array}{l}\text { Neonates are acknowledged as a vulnerable group, } \\
\text { although some individuals are skeptical of value of } \\
\text { category }\end{array}$ \\
\hline \multicolumn{3}{|l|}{ Issue characteristics } \\
\hline Severity & $\begin{array}{l}\text { Few global health organizations } \\
\text { acknowledge severity of problem }\end{array}$ & $\begin{array}{l}\text { Severity of problem is recognized: about } 4 \text { million } \\
\text { deaths every year }\end{array}$ \\
\hline Tractability & $\begin{array}{l}\text { Problem is largely perceived as } \\
\text { intractable in low-income settings }\end{array}$ & $\begin{array}{l}\text { Identification of cost-effective interventions shifts } \\
\text { perceptions on tractability }\end{array}$ \\
\hline \multicolumn{3}{|l|}{ Political context } \\
\hline Other actors & $\begin{array}{l}\text { Few global health organizations } \\
\text { address issue }\end{array}$ & $\begin{array}{l}\text { Dozens of organizations participating in addressing } \\
\text { issue, although few make it a central priority }\end{array}$ \\
\hline Policy window & $\begin{array}{l}\text { No global political agreements address } \\
\text { issue explicitly }\end{array}$ & $\begin{array}{l}\text { Recognition that Millennium Development Goal } 4 \\
\text { cannot be achieved without attention to newborn } \\
\text { survival }\end{array}$ \\
\hline
\end{tabular}

In comparison with radiological $X$-ray imaging techniques or magnetic resonance, ultrasonography was more convenient, because of unlimited examination frequency of critically sick newborns in the isolettes, and less costly, without the need for sedation and transportation of infants. ${ }^{10}$ Introduction of Doppler studies was a new advancement in the assessment of circulation in neonates in the late $1980 \mathrm{~s}^{14,15}$ This technique enabled functional follow-up of the brain, heart, liver, kidney and other organs. ${ }^{15}$ In the 1990s, a new exciting technique of 3D and 4D ultrasonography was developed, depicting neonatal organs in the third-dimension and in real-time. ${ }^{16-20}$ Brain ultrasound became the most widely used technique for evaluation of brain morphology and cerebral lesions in neonates. ${ }^{10,15}$ It can confirm prenatal diagnosis and identify not only the presence of lesions but also their type and extent. ${ }^{21}$ The use of ultrasound in cardiology made substantial improvement in the diagnostics of congenital heart defects as well as the follow-up of the critically sick newborns. Ultrasound became widely used and accepted diagnostic technique in neonatology used not only by radiologists and ultrasonographers but also as the point of care technique used by neonatologists in neonatal intensive care settings.

Because health is understood as a physical, mental and social well-being which goes much further than just the absence of acute suffering or disease, ultrasonographic screening and diagnostic activities in neonatology should be highly prophylactic regarding morphological and functional handicap of newborn child.

\section{Ultrasound in the Hands of Acute Care Neonatologists}

In his paper published in the year 2000, Evans concluded that ultrasound in neonatology is moving beyond its traditional boundaries and becoming part of the acute care doctors' diagnostic repertoire. This trend needs to be recognized in the specialty training and the ultrasound accreditation processes. ${ }^{22}$ Ultrasound can be used by neonatologists in the neonatal intensive care unit and well care nursery, but sometimes it can be performed by radiologists or other specialist in order to make or confirm the diagnosis of diseases and conditions in neonates. The use of ultrasound by neonatologists and other specialists is show $n$ in the Table $2 .^{23}$

\section{Point of Care Neonatal Ultrasound}

N eonatal cranial ultrasound has been applied for many years as the most often used point of care diagnostic imaging technique in neonatology. It has improved diagnosis cerebral condition in normal, critically sick and malformed neonates and has been useful as screening and unavoidable diagnostic imaging tool. ${ }^{24,25}$ It has been used for many years in many countries all over the world. Although there some international guidelines on neonatal cerebral ultrasound that have been published, ${ }^{26}$ lack of international ly standardized approach to the application of this kind of examination in neonates was pointed out for many years as well as the lack of the appropriate curriculum for the education of neonatologists. The example of the curriculum for advanced 
Table 2: Neonatal applications of ultrasound ${ }^{23}$

\begin{tabular}{ll}
\hline By neonatologists & $\begin{array}{l}\text { By other specialists } \\
\text { (non-neonatologists) }\end{array}$ \\
\hline Existing & Fetal \\
Neonatal cranial ultrasound & Head and brain \\
Neonatal cardiac ultrasound & Cardiac \\
Neonatal abdominal ultrasound & Chest/diaphragm \\
Neonatal hip ultrasonography & $\begin{array}{l}\text { Abdominal (kidneys } \\
\text { and bladder, pylorus, } \\
\text { ovaries, uterus, liver } \\
\text { gall bladder, spleen, } \\
\text { testes, masses, }\end{array}$ \\
& tumors) \\
& Vascular access \\
& Eyes \\
E merging & $?$ \\
Bowel & \\
Lung & \\
Endotracheal tube & \\
Potential & $?$ \\
Other catheters and nasogastric tubes & \\
Body composition & \\
\hline
\end{tabular}

head ultrasound performed by clinicians is presented in the A ppendix 1 . It is very important to point out that whenever performed it should be mentioned whether is it performed by clinician or other imaging special ist. This applies to all ultrasound findings in neonatology.

The role of echocardiography in the neonatal intensive care unit (NICU) has changed over the past few years. ${ }^{27}$ Previously, nearly all echocardiographic studies in the NICU were performed by pediatric cardiologists to diagnose or monitor congenital heart disease (CHD) and to screen for patent ductus arteriosus (PDA). ${ }^{27}$ The initial echocardiographic examination should always be a comprehensive study of both anatomy and function that is to be interpreted by a pediatric cardiologist within a reasonable time frame. Some structural defects, such as anomalous pulmonary venous return or coarctation of the aorta, can be difficult to detect using echocardiography and require extensive training and continued practice. ${ }^{27}$

Once significant congenital defects have been ruled out, more focused studies can be performed and interpreted by a trained echocardiographer for specific indications. M ore recently, neonatologists have become interested in the echocardiographic assessment of hemodynamic instability in infants. ${ }^{27}$ The terms functional echocardiography, pointof-care echocardiography and targeted neonatal echocardiography have been introduced to describe the use of echocardiography as an adjunct in the clinical assessment of the hemodynamic status in neonates. ${ }^{27}$ The increasing availability of echocardiography, with miniaturization of the technology, has resulted in more widespread use of echocardiography in NICUs around the world. ${ }^{27}$

Summary of training requirements for echocardiography in neonates are presented in the Table $3 .{ }^{27}$ Such training is missing in $55 \%$ of European NICU s, although in more than $74 \%$ of NICUs functional neonatal echocardiography has been used for many indications. ${ }^{28}$

Table 3: Summary training requirements for echocardiography in neonates ${ }^{27}$

\begin{tabular}{|c|c|c|c|c|}
\hline \multirow[t]{2}{*}{ Type of training } & \multicolumn{3}{|c|}{ Training level } & \multirow[t]{2}{*}{ Accreditation } \\
\hline & Core/basic & Advanced & Expert & \\
\hline
\end{tabular}

American College of Cardiology (ACC)/American Heart Association (AHA)/American Society of Echocardiography (ASE): pediatric echocardiography

\begin{tabular}{|c|c|c|c|c|}
\hline Number of studies & $\begin{array}{l}150 \text { studies } \\
\text { performed } \\
150 \text { studies } \\
\text { reviewed }\end{array}$ & $\begin{array}{l}200 \text { additional } \\
\text { studies performed } \\
200 \text { additional studies } \\
\text { reviewed }\end{array}$ & Not defined & None \\
\hline Duration of training & 4-6 months & Additional 9-12 months & & \\
\hline \multicolumn{5}{|c|}{ Association for European Pediatric Cardiology (AEPC): pediatric echocardiography } \\
\hline Number of studies & $\begin{array}{l}250 \text { studies } \\
\text { performed }\end{array}$ & $\begin{array}{l}750 \text { studies } \\
\text { performed in total }\end{array}$ & $\begin{array}{l}2,000 \text { studies } \\
\text { performed in } \\
\text { total }\end{array}$ & $\begin{array}{l}\text { European } \\
\text { Association of } \\
\text { Echocardiography } \\
\text { (EAE) congenital } \\
\text { echocardiography } \\
\text { exam }\end{array}$ \\
\hline Duration of training & Not defined & Not defined & Not defined & \\
\hline \multicolumn{5}{|c|}{ Targeted Neonatal Echocardiography (TNE) Guidelines } \\
\hline Number of studies & $\begin{array}{l}150 \text { studies } \\
\text { reviewed } \\
150 \text { studies } \\
\text { peformed }\end{array}$ & $\begin{array}{l}150 \text { studies } \\
\text { reviewed } \\
150 \text { studies } \\
\text { performed }\end{array}$ & Not defined & None \\
\hline Duration of training & 4-6 months & Additional 4-6 months & Not defined & None \\
\hline
\end{tabular}


Appendix 1: Advanced clinician performed neonatal ultrasound (CPNU $)^{40}$

Purpose: This program is designed to cover the theoretical and practical curriculum for advanced functional imaging of the neonatal heart and brain as well as basic imaging of the abdominal organs and central line localization.

Prerequisites: Learners should have completed the physical principles and instrumentation unit and the introduction to CPNU unit, including submission of their logbook.

Training: Mandatory attendance at a 2 days Australian Society of Ultrasound in Medicine approved Advanced CPNU course.

Assessments: Learners are required to perform supervised ultrasound scans, document them in a logbook and submit the logbook in order to complete the unit.

\section{Course Objective}

Scanning the neonate

On completing this unit, delegates should be able to:

- Demonstrate an understanding of the common conventions of neonatal scanning including image optimization.

- Competently record a series of images to clearly demonstrate normal anatomy.

- Demonstrate proficiency in assessing and interpreting normal and abnormal neonatal cardiac hemodynamics.

- Understand limitations to the accuracy of hemodynamic measurements.

- Recognize common patterns of CHD.

- Recognize common abnormalities found on cerebral ultrasound.

- Use ultrasound to locate intravascular lines.

- Recognize abnormal fluid collections in pleural and peritoneal space and common renal and hepatic abnormalities.

- Recognize when an examination is incomplete and needs to be repeated.

Demonstrate competency in:

- Interpreting heart ultrasound findings to determine the significance of ductal shunting.

Cranial ultrasound

- Using coronal and sagittal cranial ultrasound windows via anterior fontanelle to demonstrate normal anatomical structures.

- Recognizing intracranial bleeding with competent assessment of subependymal, intraventricular and parenchymal bleeding.

- Recognizing common structural abnormalities of cerebral development.

- Performing and interpreting Doppler studies of the anterior and middle cerebral artery.

- Interpreting cranial ultrasound findings in relation to the clinical scenario.

\section{Neonatal cranial ultrasound}

i. Anatomy

Normal cranial anatomy of the brain will be presented, including:

- Ventricular structure

- Anatomy of major sulcal patterns

- Thalamus

- Caudate nucleus

- Corpus callosum

- Cerebellum

ii. Skills

Courses will teach learners the following imaging skills:

- Obtaining coronal and sagittal cranial ultrasound windows via anterior fontanelle to demonstrate normal anatomical structures.

- Recognizing intracranial bleeding with competent assessment of subependymal, intraventricular and parenchymal bleeding.

- Recognizing common structural abnormalities of cerebral development.

- Performing and interpreting Doppler studies of the anterior and middle cerebral artery.

iii. Recording

Courses will teach learners the common conventions of cranial scanning and how to competently record a series of images to clearly demonstrate normal cranial anatomy or any abnormality.

iv. Limitations

All scans should be reviewed by a competent scanner (or pediatric radiologist). There is a need to recognize when referral is mandatory because of an incomplete scan or a possible anatomical or functional abnormality. Important management decisions should not be made without such experienced review.

v. Interpretation

Courses will teach learners to interpret the cranial ultrasound findings in relation to the clinical scenario. Important topics

covered will include:

- Grading common patterns of peri/intraventricular hemorrhage.

- Recognizing common structural abnormalities of cerebral development.

- Recognizing the common parenchymal and Doppler changes seen in the asphyxiated infant.

\section{Neonatal cardiac ultrasound}

\section{i. Anatomy}

Normal anatomical structure of the heart as it relates to the standard echocardiographic windows will be presented, including:

- Surface anatomy of the heart and great vessels

- The three-dimensional structure of the heart

- Derivation of the two-dimensional images obtained using heart ultrasound

- Anatomy of the inflow tracts

- Anatomy of the great vessels (outflow tracts)

- Anatomy of the heart valves

- Anatomy of the cardiac chambers 
Contd...

ii. Skills

Courses will teach learners the following image optimization skills related to hemodynamic assessment:

- Assessing size and shunt direction of the PDA

- Measuring right and left ventricular output

- Measuring superior vena cava flow

- Assessing myocardial function using M-mode and other means

- Assessing significance and direction of interatrial shunting

- Measuring or assessing pulmonary artery pressure using tricuspid incompetence, ductal shunt velocities, or pulmonary artery Doppler acceleration times.

- Recognizing common CHD, including:

When to involve a pediatric cardiologist as set out in the 'appropriate use' statement.

- Recognizing indirect markers to the presence of CHD. For example, large or small vessels and chambers, and abnormal movement of myocardium or valves.

- Assessing infants with cyanosis of unknown cause.

- Recognizing echocardiographic features of persistent pulmonary hypertension (PPHN).

- Recognizing common cyanotic CHD that can mimic PPHN [e.g. total anomalous pulmonary venous connection (TAPVC), transposition of great arteries (TGA)].

- Recognizing other common cyanotic CHD, including ductal dependent pulmonary circulations.

- Assessing infants with respiratory distress, heart failure and or shock.

- Recognizing common ductal dependent systemic circulation lesions.

- Recognizing other common CHD, including pulmonary stenosis, Fallot's Tetralogy and atrioventricular canal defects.

- Recognizing muscular and perimembranous ventricular septal defects.

iii. Recording

Courses will teach learners the common conventions of cardiac scanning and how to competently record a series of images to clearly demonstrate normal cardiac anatomy.

iv. Limitations

Advanced CPNU courses will discuss:

- Understanding limitations to the accuracy of hemodynamic measurements.

- Recognizing when an examination is incomplete and needs to be repeated.

During the introductory stage, all scans should be reviewed by a competent scanner (or pediatric cardiologist). There is a need to recognize when to refer because of an incomplete scan or a possible anatomical or functional abnormality. Important management decisions should not be made without such experienced review.

v. Interpretation

Courses will teach learners the skills needed to competently interpret the heart ultrasound findings in relation to the following

criteria to determine the significance of ductal shunting:

- Interpreting abnormal and normal ventricular outputs

- Interpreting normal and abnormal superior vena cava flow

- Interpreting normal and abnormal myocardial function

- Interpreting normal and abnormal atrial shunting

- Interpreting normal and abnormal pulmonary artery pressures.

\section{Neonatal abdominal ultrasound}

\section{i. Anatomy}

Normal abdominal anatomy will be presented, including:

- Anatomy and relationships of major organs

- Anatomy and relationships of inferior vena cava (IVC) and abdominal aorta

ii. Skills

Courses will teach learners the following imaging skills:

- IVC and abdominal aorta including umbilical catheter and percutaneous intravenous catheter tip location

- Ascites/pleural effusions

- Locating and identifying the kidneys

- Locating the bladder, and assessing relative volume.

iii. Recording

Courses will teach learners the common conventions of abdominal scanning and how to competently record a series of images to clearly demonstrate normal abdominal anatomy.

iv. Limitations

All scans should be reviewed by a competent scanner (or pediatric radiologist). There is a need to recognize when referral is mandatory because of an incomplete scan or a possible anatomical or functional abnormality. Important management decisions should not be made without such experienced review.

v. Interpretation

Courses will teach learners the skills needed to competently interpret the ultrasound findings in relation to the clinical scenario, including:

- Recognizing and localizing fluid in the pleural, peritoneal and pericardial spaces.

- Recognizing common renal abnormalities, such as pelvic dilatation, hydronephrosis and large or small kidneys.

- Recognizing and assessing volume of bladder contents.

- Assessing for intravenous catheter tip position, particularly to exclude an intracardiac tip position. 
Contd...

\section{Limitations and Pitfalls}

Standards and appropriate use of Neonatal Clinician Performed Ultrasound

It is expected that the CCPU in neonatal ultrasound is to be used for provision of ultrasound at the point of care in a neonatal intensive care unit to enhance the clinical care of the infant and not to raise revenue.

\section{Limitations of Use}

Holders of the CCPU in neonatal ultrasound are expected to consult and request appropriate advice by a pediatric cardiologist or radiologist under the following circumstances:

\section{By a Pediatric Cardiologist}

- If the primary clinical concern is the possibility of CHD.

- If specific treatment is being instituted for CHD based on a clinician performed ultrasound (CPU).

- If transfer to a pediatric cardiology unit is being planned based on a CPU.

- If the clinical findings or course are 'NOT' consistent with the CPU findings.

- If the baby is no longer in an Neonatal Intensive Care Unit setting, e.g. after discharge.

\section{By a Radiologist}

- For documentation and confirmation of abnormal cranial ultrasound results.

- For provision of routine cranial ultrasound services if this already exists. Performance of a CPU is not expected to be equivalent to a study performed by an imaging consultant and as such should not be relied upon to exclude significant pathology.

\section{Documentation}

It is recommended that documentation of CPU studies specifically mention that ultrasound scans are clinician performed to distinguish them from studies by a consultative diagnostic imaging specialist. So, document 'clinician performed cardiac ultrasound' or 'clinician performed cerebral ultrasound' and avoid terms, such as 'echocardiogram'.

\section{Standards for CCPU in Neonatal Ultrasound Teaching Institutions and Courses}

\section{Recognized Institutions}

Recognized institutions for training in the CCPU (neonatal ultrasound) should have the following:

- Be associated with a neonatal intensive care unit

- Close affiliation with a radiology and pediatric cardiology service

- At least one clinician whose qualification is recognized by the ASUM council as a qualification for training

- Access to a level of ultrasound equipment to allow appropriate quality accuracy and repeatability of scanning. Equipment should be no older than 10 years.

\section{Assessment and Logbook}

- Documentation to show attendance and completion of 'advanced CPNU' CCPU course.

- Submission of a minimum of five ultrasound scans: four cardiac and one cerebral, in digital format (DICOM or .avi) on USB stick or CD for review by the examiner. These scans should include all the views as defined in the 'CCPU Neonatal Outline of Level 2 (advanced) cardiac scan,' and available on the ASUM website, www.ASUM.com.au.

- Completion of logbook to satisfy requirements as set out below.

\section{Logbook Requirements}

- The logbook requirements should be completed and submitted within 2 years of finishing an ASUM accredited 'advanced CP NU' CCPU course.

- The advanced logbook may be recorded in continuity with the 'Introduction' logbook.

- Complete 25 cardiac ultrasounds 25 cerebral ultrasounds and 10 abdominal scans to show the ability to perform advanced cerebral, functional cardiac and basic abdominal scanning. All scans should be clinically indicated.

- At least half of these studies should demonstrate some pathology.

- These studies should be stored digitally for review, if required.

- These studies should all be signed off by an ASUM approved supervisor, which includes a recertified neonatal CCPU, anyone on the neonatal supervisor register, DDU, DMU, AMS or other recognized ultrasound qualification or specialist radiologist or cardiologist.

The documentation in the logbook must include:

- Date of study and initials of patient

- Brief summary of findings

- Signature of supervisor

- A summary of the number of each type of scan performed demonstrating compliance with requirements for logbook (absolute, at least half with pathology).

Documentation to be presented with the logbook and the scans in digital format demonstrating completion of these requirements

must also include:

- Evidence of satisfactory completion of training sessions within a recognized institution in neonatal ultrasound.

- Evidence that all of the cases have been signed off by a suitably qualified clinician (see above).

- A completed ASUM Neonatal Logbook Assessment for CCPU (neonatal) form available at http://www.asum.com.au/newsite/ Files/Documents/Education/CCPU/NewCCPU/6.\%20Logbook\%20Templates/Logbook\%20Assessment\% 20checklists/ Assessment $\% 20$ Checklist_2012\%20Neonatal.pdf

The preference of the neonatal CCPU committee is that there should be direct supervision of learners by an accredited supervisor. If learners have problems finding a supervisor to sign off the logbook, the committee will be prepared to consider direct electronic submission of ultrasound scans to demonstrate competence. 
Neonatal abdominal ultrasound is very important in the diagnosis of renal and other congenital malformations as well as some infections and other conditions like necrotizing enterocolitis. ${ }^{29} \mathrm{~B}$ esides that some birth injuries like adrenal gland hemorrhage. ${ }^{30}$

Use of ultrasound in the diagnosis of the developmental dysplasia of the hip (DDH) in neonates is still controversial. There is still insufficient evidence to give clear recommendations for practice. ${ }^{31}$ There is inconsistent evidence that universal ultrasound results in a significant increase in treatment compared to the use of targeted ultrasound or clinical examination alone. ${ }^{31} \mathrm{~N}$ either of the ultrasound strategies have been demonstrated to improve clinical outcomes including late diagnosed DDH and surgery. ${ }^{31}$ The studies are substantially underpowered to detect significant differences in the uncommon event of late detected DDH or surgery. ${ }^{31}$ For infants with unstable hips or mildly dysplastic hips, use of delayed ultrasound and targeted splinting reduces treatment without significantly increasing the rate of late diagnosed DDH or surgery. ${ }^{31,32}$

Respiratory distress syndrome due to hyposurfactosis is still one of the most severe and most frequent morbidity in premature infants causing severe mortality. ${ }^{33}$ The diagnosis of the condition rely mainly on thoracic X-ray, while the role of usl trasound is increasing. ${ }^{34-36}$

UItrasound-guided umbilical catheter placement is a faster method to place catheters requiring fewer manipulations and $\mathrm{X}$-rays when compared with conventional catheter placement, although it is still not widely used due to the lack of proper training. ${ }^{37}$ R eal-time ultrasound could be used to place a peripherally inserted central catheter (PICC). This method of placement of PICC reduces catheter insertion duration, and is associated with fewer manipulations and radiographs when compared with conventional placement. ${ }^{38}$

Ultrasound provides a noninvasive, portable method of assessing changes in subcutaneous adipose tissue and muscle accretion and appears sufficiently sensitive to detect influences of macronutrient intakes on accretion rates in preterm infants from birth. ${ }^{39}$ The method warrants further investigation as a bedside tool for measuring body composition of preterm infants. ${ }^{39}$

\section{CONCLUSION}

From the beginning of its use in neonatology, ultrasound is used more frequently and for many indications. Number of indications is increasing from year to year, while the training opportunities and curricula are not following the same trend. Nowadays ultrasound has been used for determination of functional hemodynamics in critically sick neonates which increases educational burden on the young neonatologists. This only applies to the developed countries where neonatology is well developed, while in low-income so called developing countries some basic health problems of neonates have not been solved and there is substantial lack of heal th care professionals and equipment as well.

\section{REFERENCES}

1. L awn JE, Kerber K, Enweronu-L aryea C, M assee B ateman 0. Newborn survival in low resource settings--are we delivering? BJOG 2009 Oct; 116(Suppl 1):49-59.

2. LawnJE, Cousens S, Zupan J. L ancet N eonatal Survival Steering Team. 4 million neonatal deaths: W hen? Where? W hy? L ancet $2005 \mathrm{M}$ ar;365(9462):891-900.

3. Lawn JE, Cousens SN, D armstadt GL, B hutta ZA, M artines J, Paul V, K nippenberg R, Fogstad H. L ancet N eonatal Survival Series steering. 1 year after The $L$ ancet Neonatal Survival Series- was the call for action heard? Lancet 2006 May; 367(9521):1541-1547.

4. L awn JE, W ilczynska-K etende K, Cousens SN. Estimating the causes of 4 million neonatal deaths in the year 2000. Int J Epidemiol 2006 J un;35(3):706-718.

5. Darmstadt GL, B hutta ZA, Cousens S, A dam T, W alker N, de B ernis L. L ancet N eonatal Survival Steering Team. Evidencebased, cost-effective interventions: how many newborn babies can we save? Lancet 2005 M ar;365(9463):977-988.

6. Lawn JE, Gravett MG, N unes TM, Rubens CE, Stanton C. GAPPS Review Group. Global report on preterm birth and stillbirth: definitions, description of the burden and opportunities to improve data. B M C Pregnancy Childbirth 2010 Feb; 10(Suppl 1): S1.

7. Lawn J. Why focus on babies? Inter Press Service: A pr 2013. A vailable from: http://www.globalissues.org/news/2013/04/08/ 16273.

8. Shiffman J. Issue attention in global health: the case of new born survival. Lancet 2010 J un; 375(9730):2045-2049.

9. Dubowitz LM S, L evene M I, M orante A, Palmer P, Dubowitz $V$. N eurologic signs in neonatal intraventricular hemorrhage: a correlation with real-time ultrasound. J Pediatr 1981 J ul;99(1):127-133.

10. Fischer A Q, A nderson J C, Shuman RM, Stinson W. Pediatric neurosonography: clinical, tomographic and neuropathologic correlates. N ew Y ork, Chichester, B risbane, T oronto, Singapore: A Wiley Medical Publication; 1985.

11. L evene M, Dowling S, Graham M, Fogelman K, Galton M, Philips M . Impaired motor function (clumsiness) in 5-year-old children: correlation with neonatal ultrasound scans. A rch Dis Child 1992 J un;67(6):687-690.

12. L evene M I, W igglesw orth JS, D ubowitz V. Cerebral structure and intraventricular hemorrhage in the neonate: a real-time ultrasound study. A rch Dis Child 1981 J un;56(6):416-424.

13. Papile $L A, B$ urstein J, Burstein $R, K$ offler $H$. Incidence and evolution of subependymal and intraventricular hemorrhage: a study of infants with birth weights less than 1,500 gm. J Pediatr 1978 A pr;92(4):529-534.

14. N ewman PG, Rozycki GS. The history of ultrasound. Surg Clin North A m 1998 A pr;78(2):179-195.

15. Peng SS, Lin JH, LeeWT, Tsao PN, Shih JC, Liu HM, Li Y W, H sieh FJ, T sou KI. 3-D power D oppler cerebral angiography in 
neonates and young infants: comparison with 2-D Doppler angiography. Ultrasound M ed Biol 1999 J ul;25(6):947-951.

16. Kampmann W, Walka M M, Vogel M, Obladen M. 3-D sonographic volume measurement of cerebral ventricular system: in vitro validation. Ultrasound M ed Biol 1998 Oct;24(8):1169-1174.

17. Kurjak A, H afner T, Kos M, K upesic S, Stanojevic M. Threedimensional sonography in prenatal diagnosis: a luxury or necessity. J Perinat M ed 2000;28(3):194-209.

18. M erz E. A ktuelle technische M öglichkeiten der 3D-Sonographie in der Ginäkologie und Geburtshilfe. Ultrashal in Med 1997;18(5):190-195.

19. Nagdyman N, Walka M M , Kampmann W, Stowver B, O bladen M. 3-D ultrasound quantification of neonatal cerebral ventricles in different head positions. Ultrasound M ed Biol 1999 Jul;25(6):895-900.

20. Nelson TR, Pretorius DH. Three-dimensional ultrasound imaging. Ultrasound M ed Biol 1998 Nov;24(9):1243-1270.

21. M ercuri E, Dubowitz L, Paterson B rown S, Cowan F. Incidence of cranial ultrasound abnormalities in apparently well neonates on postnatal ward: correlation with antenatal and perinatal factors and neurological status. A rch D is Child Fetal N eonatal Ed 1998 Nov;79(3):F185-F 189.

22. Evans $\mathrm{N}$. Echocardiography on neonatal intensive care units in A ustralia and New Zealand. J Paediatr Child Health 2000 A pr;36(2):169-171.

23. $\mathrm{Kim} \mathrm{J} \mathrm{H.} \mathrm{Introducing} \mathrm{neonatologist} \mathrm{performed} \mathrm{ultrasound} \mathrm{to} \mathrm{the}$ NICU. San Diego, CA : U C San Diego M edical Center. A vailable from: http://healthcare-professionals.sw.org/resources/docs/ division-of-education/events/neonatology-conference/2012/ B reakout.NEC.Kim.pdf.

24. Rennie J M, Hagmann CF, Robertson NJ. Neonatal cerebral investigation. Cambridge: Cambridge University Press; 2008.

25. Volpe JJ. Neurology of the newborn. 5th ed. Philadelphia: Saunders Elsevier; 2008.

26. A merican Institute of U Itrasound in M edicine. A IU M practice guideline for the performance of neurosonography in neonates and infants. J Ultrasound M ed 2010 Jan;29(1):151-156.

27. M ertens $L$, Seri I, M arek J, A rlettaz R, B arker $P, M$ cNamara $P$, M oon-Grady AJ, Coon PD, N oori S, Simpson J, et al. Targeted Neonatal Echocardiography in the N eonatal Intensive Care U nit: practice guidelines and recommendations for training. W riting Group of the A merican Society of Echocardiography (ASE) in collaboration with the European Association of Echocardiography (EAE) and the Association for European Pediatric Cardiologists (A EPC). J A m Soc Echocardiogr 2011 Oct;24(10):1057-1078.

28. Roehr CC, Te Pas A B, Dold SK, Breindahl M, Blennow M, Rüdiger M , G upta S. Investigating the European perspective of neonatal point-of-care echocardiography in the neonatal intensive care unit-a pilot study. Eur J Pediatr 2013 Jul;172(7):907-911.
29. B ohnhorst B. U sefulness of abdominal ultrasound in diagnosing necrotising enterocolitis. A rch D is Child F etal N eonatal Ed 2013 A pr 9. [Epub ahead of print].

30. Y ao W, Li K, X iao X, Zheng S, Chen L. Neonatal suprarenal mass: differential diagnosis and treatment. J Cancer Res Clin Oncol 2013 Feb;139(2):281-286.

31. Shorter D, Hong T, Osborn DA. Screening programmes for devel opmental dysplasia of the hip in new born infants. Cochrane Database Syst Rev 2011 Sep 7;(9):CD 004595.

32. Bracken J, Ditchfield M. Ultrasonography in developmental dysplasia of the hip: what have we learned? Pediatr Radiol 2012 Dec;42(12):1418-1431.

33. Sun $H, X u F, X$ iong $H, K$ ang $W, B$ ai Q, Zhang $Y$, Zhou $C$, Zhuang $F$, W ang $X$, Zhu $C$. Characteristics of respiratory distress syndrome in infants of different gestational ages. Lung 2013 Aug;191(4):425-433.

34. Copetti R, Cattarossi L, M acagno F, V iolino M , Furlan R. L ung ultrasound in respiratory distress syndrome: a useful tool for early diagnosis. N eonatology 2008;94(1):52-59.

35. Raimondi $F, M$ igliaro $F$, Sodano A, U mbaldo A, Romano A, Vallone $G, C$ apasso L. Can neonatal lung ultrasound monitor fluid clearance and predict the need of respiratory support? C rit Care $2012 \mathrm{~N} \mathrm{ov} ; 16(6):$ R 220.

36. Lovrenski J. L ung ultrasonography of pulmonary complications in preterm infants with respiratory distress syndrome. Ups J M ed Sci $2012 \mathrm{M}$ ar;117(1):10-17.

37. Fleming $\mathrm{SE}, \mathrm{K}$ im JH. Ultrasound-guided umbilical catheter insertion in neonates. J Perinatol $2011 \mathrm{M}$ ay;31(5):344-349.

38. Katheria AC, Fleming SE, K im JH. A randomized controlled trial of ultrasound-guided peripherally inserted central catheters compared with standard radiograph in neonates. J Perinatol 2013 J un 13. [E pub ahead of print].

39. MCL eod G, Geddes D, Nathan E, Sherriff J, Simmer K, Hartmann P. Feasibility of using ultrasound to measure preterm body composition and to assess macronutrient influences on tissue accretion rates. Early H um Dev 2013 A ug;89(8):577-582.

40. Australasian Society for Ultrasound in M edicine. Promoting excellence in ultrasound. Certificate in Clinician Performed Ultrasound (CCPU). A dvanced Clinician Performed N eonatal UItrasound. July 2012. A vailable from: http://www .asum.com. au/new site/E ducation. php? $p=$ CCPU $-N$ eonatal.

\section{ABOUT THE AUTHOR}

\section{Milan Stanojevic}

Department of Obstetrics and Gynecology, M edical School U niversity of Zagreb, Neonatal Unit, Clinical Hospital, Sv. Duh, Zagreb, Sv. Duh 64, 10000 Zagreb, Croatia, DIU, Libertas, Dubrovnik International University, Croatia, Phone: ++38513712316, Fax: ++38513745534, e-mail: milan.stanojevic@optinet.hr 